\title{
Combined ultrasonic aspiration and saline-linked radiofrequency precoagulation: a step toward bloodless liver resection without the need of liver inflow occlusion: analysis of 313 consecutive patients
}

Evangelos Felekouras ${ }^{1}$, Athanasios Petrou ${ }^{2}, K_{\text {Kyriakos Neofytou }}^{3 *}$, Alexandros Giakoustidis ${ }^{4}$, Jessamy Bagenal ${ }^{5}$, Ferdinando Cananzi ${ }^{3}$, Emmanouel Pikoulis ${ }^{1}$ and Satvinder Mudan ${ }^{3}$

\begin{abstract}
Background: Hemorrhage is undoubtedly one of the main factors contributing to morbidity and mortality in liver resections. Vascular occlusion techniques are effective in controlling intraoperative bleeding, but they cause liver damage due to ischemia. We evaluated the effectiveness and safety of using a combined technique for hepatic parenchymal transection without liver inflow occlusion.

Methods: Three hundred and thirteen consecutive patients who underwent liver resection in four hepato-pancreato-biliary units. Hepatic parenchymal transection was carried out using a combined technique of saline-linked radiofrequency precoagulation and ultrasonic aspiration without liver inflow occlusion.

Results: During the study period 114 minor and 199 major hepatic resections were performed. The mean amount of intraoperative blood loss was $377 \mathrm{ml}$ (SD $335 \mathrm{ml}$, range 50 to 2,400 ml) and the blood transfusion rate was 10.5\%. The median amount of blood loss during parenchymal transection and parenchymal transection time was $222 \mathrm{ml}$ (SD $224 \mathrm{ml}$, range 40 to 2,100 ml) and 61 minutes (range 12 to 150 minutes) respectively. There were two postoperative deaths (0.6\%). Complications occurred in 84 patients (26.8\%) and most complications were minor.

Conclusions: Combined technique of saline-linked radiofrequency ablation and ultrasonic aspiration for liver resection is a safe method for both major and minor liver resections. The method is associated with decreased blood loss, reduced postoperative morbidity, and minimal mortality rates. We believe that this combined technique is comparable to other techniques and should be considered as an alternative.
\end{abstract}

Keywords: Liver resection, Blood loss, Pringle, Complications, Ultrasonic aspiration, Radiofrequency

\section{Background}

Hepatic resection is widely accepted as the only potential curative treatment for patients with a wide variety of liver conditions [1-5]. Hemorrhage is one of the main factors contributing to morbidity and mortality in major liver resections [6-11]. However, bleeding and subsequent

\footnotetext{
* Correspondence: kneophy2@gmail.com

${ }^{3}$ Department of Academic Surgery, Upper GI/HPB Unit, Royal Marsden Hospital, Fulham Road, London SW3 6JJ, UK

Full list of author information is available at the end of the article
}

blood transfusion may increase the recurrence rate and reduce the survival rate for malignant diseases [7,12-14].

The concept of introducing bloodless techniques to facilitate surgical resection of liver tumors has stimulated hepatobiliary surgeons to experiment with new procedures. Initial techniques involved clamping of outflow (total vascular exclusion), and inflow vessels (Pringle maneuver), aiming to reduce bleeding during parenchymal transaction [15-17]. The Pringle maneuver, which involves the control of the hepatic vascular inflow by clamping the hepatoduodenal ligament, represents the most simple of 
these methods of vascular control [18]. This maneuver represents a valuable tool for managing intraoperative bleeding, but at the same time places the patient at a high risk of liver damage due to ischemic reperfusion syndrome and many other complications [18-24]. Consequently, the use of liver occlusion has reduced among liver surgeons but is still used in a few centers. One European survey revealed that $19 \%$ of surgeons apply the Pringle maneuver routinely [25].

The need to avoid the complications related to major vascular occlusions has resulted in the use of liver parenchymal transection without clamping techniques. Parenchymal transection tools such as the Cavitron ultrasonic surgical aspirator $\left(\mathrm{CUSA}^{\circ}\right)$, saline-linked radiofrequency precoagulation, harmonic scalpel, bipolar scissors, Ligasure device, hydrodissectors, or monopolar floating ball, single or in combinations, are commonly used by experienced surgical teams and the published results are encouraging. The combination of new transection tools, concomitant anesthetic and critical care improvements have dramatically reduced morbidity and mortality rates.

We report the efficacy and complications of a combined technique for liver resection without liver inflow occlusion in 313 consecutive patients with primary or metastatic liver malignancies. This technique uses combinational Cavitron ultrasonic surgical aspirator (CUSA; ValleyLab, Boulder, CO, USA) and a saline-linked radiofrequency dissecting sealer (Aquamantys $\mathrm{s}^{\circ}$ ).

\section{Methods}

From September 2007, to March 2013, all patients who underwent liver resection for liver malignancies, with combined technique using $\mathrm{CUSA}^{\bullet}$ and Aquamantys ${ }^{\oplus}$ at the following 4 hepato-pancreato-biliary (HPB) units: 1 ) Department of Academic Surgery, Royal Marsden Hospital, London, UK, 2) The London Clinic Hospital, London, UK, 3) Nicosia Department of Surgery, Division of HPB Surgery, Nicosia General Hospital, Nicosia, Cyprus, 4) First Department of Surgery, University of Athens Medical School, Laikon Teaching Hospital, Athens, Greece have been included. During this period, this combined technique was used by three HPB surgeons (FE, PA, MS).

In accordance with international guidelines, all the patients underwent the necessary preoperative assessment of their disease, including spiral computed tomography, magnetic resonance imaging, and/or positron emission tomography.

Patient data was collected retrospectively and included demographic details, histological type and number of tumors, surgical procedure, overall operating time, parenchymal transection time, overall amount of intraoperative blood loss (IBL) and blood loss during parenchymal transaction (PTBL). Major and critical abnormalities of preoperative and postoperative liver function tests, intraoperative and postoperative complications, mortality rate, the length of hospital stay, and outcome were also recorded. Post hepatectomy liver failure was defined as the presence of serum bilirubin $>50 \mu \mathrm{mol} / \mathrm{l}$ and prothrombin index $<50 \%$ in the fifth postoperative day according to the '50-50 criteria' [26].

The resection time was defined as the time from the start of $\mathrm{CUSA}^{\circ}$ to the completion of parenchymal transection. The overall blood loss was estimated by weight of the surgical swabs, the amount of blood in the suction system and the $\mathrm{CUSA}^{\circ}$ suction container following the entire hepatectomy. Blood loss during liver parenchyma transection was recorded in a similar way. Blood was transfused accordingly to maintain the hematocrit above 28 to $30 \%$ perioperatively or if the patient developed hemodynamic instability as a result of blood loss.

This retrospective analysis of liver resection using a combination of $\mathrm{CUSA}^{\circ}$ and Aquamantys devices without the need for the Pringle maneuver focuses on the following outcomes; intraoperative blood loss, parenchymal transection blood loss, need for packed red blood cell (PRBC) transfusion, length of liver resection time and postoperative morbidity and 30-day mortality.

For each participating institution, the study was approved by the local ethics committee and Institutional Review Board.

\section{Operative technique}

Incisions used were a modified right subcostal (J shape), bilateral subcostal, or Mercedes-like. Central venous pressure was maintained at a low level (usually below $5 \mathrm{mmHg}$ during the parenchyma transaction) to avoid backflow bleeding and to facilitate better liver tissue manipulation. To obviate air embolism, the hepatic resection was performed with the patient in a 15-degree Trendelenburg position. Minimum accepted urine output was defined at $25 \mathrm{ml}$ /hour. Blood pressure to achieve these demands was maintained by either volume or vasopressor drug infusion whenever necessary.

In all cases, after exploration of the abdominal cavity to exclude extrahepatic or peritoneal disease, operative ultrasound was used to define the tumor, to exclude preoperatively undetected lesions and to mark the plane for liver parenchymal transection. Subsequently, the liver was mobilized according to the size and site of the lesion to be resected.

For major hepatectomies the ipsilateral major hepatic veins were encircled with vessel loops. Additionally, when an anatomic resection was planned, hilar dissection was performed. The ipsilateral branch of the hepatic artery, portal vein, and common bile duct were encircled but not divided until the parenchymal dissection reached that point. Hilar dissection was not performed for nonanatomical hepatectomy. 
The liver parenchyma was divided by CUSA ${ }^{\oplus}$. During parenchymal dissection the hepatic lobe or segment that was being resected was gently retracted by the assistant in order to separate the cut surfaces of the liver for optimal exposure (open book technique). A second surgeon held the Aquamantys ${ }^{\oplus}$ for coagulation and hemostasis (Figure 1). The Aquamantys $s^{\oplus}$ system, which is a bipolar sealer, delivers radiofrequency energy and saline simultaneously to the surgical field in order to provide hemostasis or sealing across exposed tissue. The radiofrequency energy heats tissues to around $100^{\circ} \mathrm{C}$. As a result of the heat, the collagen in the blood vessel walls shrinks, causing hemostasis. At the same time the saline, which is delivered to the surgical field, prevents charring with eschar formation. The device was efficient in controlling the small bleeding vessels within the liver parenchyma. Larger vessels and large intrahepatic bile ducts were either ligated or clipped.

For major hepatectomies, the ipsilateral hepatic artery, portal vein branches and bile duct branches were ligated intrahepatically during parenchymal transection. In addition, for major hepatectomies, the major hepatic veins were either suture-ligated and divided or divided using endovascular staplers at the end of parenchymal transection. Drains were placed in all patients.

\section{Statistic analysis}

We used SPSS statistical software, version 12 (SPSS Inc, Chicago, IL, USA), for data analysis. Common statistics were applied in order to estimate the significance of the results. Chi-square test, Mann-Whitney non-parametric test, and the Fischer's exact test were used as appropriate. Differences were considered to be significant if $P<0.05$.

\section{Results}

Three hundred and thirteen patients were included in the series (137 female and 176 males). The median age

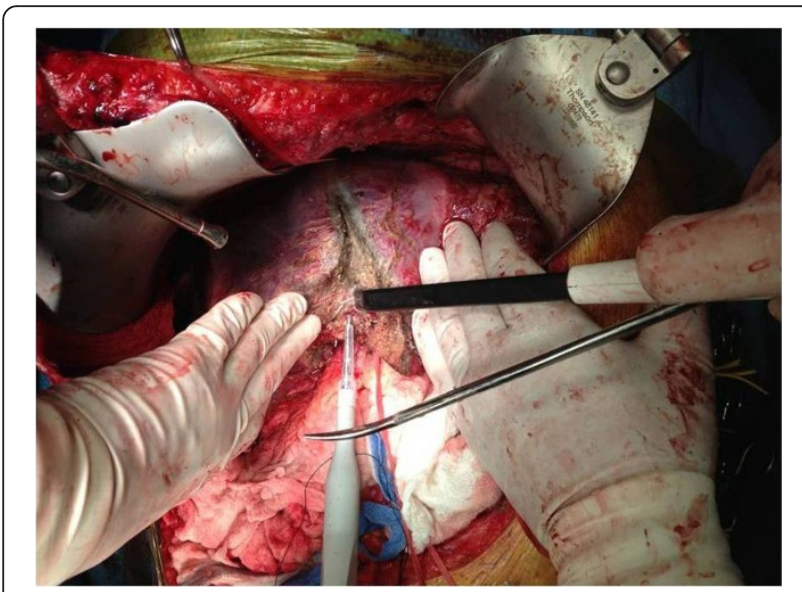

Figure 1 Hepatic parenchymal transection using CUSA ${ }^{\circledR}$ and Aquamantys ${ }^{\circledR}$. was 62 years (range 31 to 85 years). The median age among patients who underwent major liver resections (a resection of 3 segments or more) was 61 years and among patients undergoing minor liver resections (a resection of 2 or fewer segments) was 63 years ( $P$-value 0.29 ). The majority of the patients (247 patients; $78.9 \%$ ) had colorectal liver metastases (CRLM) and the rest had non-colorectal liver metastases (12 patients; 3.8\%), hepatocellular carcinoma (24 patients; $7.7 \%)$, cholangiocarcinoma (25 patients; $8 \%$ ), and gallbladder carcinoma (5 patients; $1.6 \%$ ). The patient and tumor characteristics are given in Table 1.

We performed 199 (63.58\%) major hepatectomies and 114 (36.42\%) minor hepatectomies (Table 2). One hundred and five (33.5\%) hepatectomies were performed at the Royal Marsden Hospital, 80 (25.6\%) at the The London Clinic Hospital, 48 (15.3\%) at the Nicosia General Hospital and 80 (25.6\%) in Laikon Teaching Hospital. The proportion of different tumor types $(P<0.001)$ varied in each of the 4 HPB units; however the type of operation (major versus minor liver resection) regarding each tumor type was the same $(P>0.05)$. Forty-two re-do hepatectomies were successfully performed (41 of recurrent CRLM and 1 of non-colorectal liver metastases). In addition, 41 of the patients suffering from CRLM underwent a synchronous liver resection in combination with colon resection. The liver lesions per patient rate, was statistically significant for the patients who underwent major liver resections compared to the patients who underwent minor liver resections ( $P$-value 0.016$)$ (Table 1$)$.

In Tables 1 and 2, it is clearly demonstrated that for patients suffering from hepatocellular carcinoma, hilar/ intrahepatic cholangiocarcinoma, and gallbladder carcinoma that major hepatectomy as a treatment decision was more frequent compared to patients suffering from liver metastasis (96.29 versus $56.75 \%, P$-value $<0.001)$. When comparing the type and the extent of liver resection among patients with CRLM with those with noncolorectal liver metastases it is observed that major hepatectomies were more frequently performed in the first group of patients (42.1 versus $25 \%, P=0.023$ ).

The overall operative time (mean) was 210 minutes (minimum 90 minutes, maximum 550 minutes). The mean parenchymal transection time was 51 minutes (minimum 18 minutes, maximum 120 minutes). The operative time for parenchymal transection was affected due to the raw liver surface. Major hepatectomies were prolonged with mean parenchymal transection time 69 minutes and range 48 to 120 minutes compared to minor liver resections; mean 29 minutes, range 18 to 52 minutes $(P<0.001)$.

The mean overall intraoperative blood loss was $377 \mathrm{ml}$ (SD $335 \mathrm{ml}$, range 50 to 2,400 $\mathrm{ml}$ ), and the mean blood loss during parenchymal transection was $223 \mathrm{ml}$ (SD $224 \mathrm{ml}$, range 40 to $2,100 \mathrm{ml}$ ) (Table 3). Amongst the 
Table 1 Patient and tumor characteristics

\begin{tabular}{|c|c|c|c|c|}
\hline \multirow[t]{2}{*}{ Characteristic } & \multicolumn{3}{|c|}{ Finding } & \multirow[t]{2}{*}{$P$-value } \\
\hline & Major Hepatectomy $^{a}$ & Minor Hepatectomy ${ }^{\mathbf{b}}$ & Total & \\
\hline Age, mean (SD), (minimum-maximum) years & 61 (10.74) (31 to 85) & 62.55 (10.20) (37 to 82) & $61.57(10.56)$ (31 to 85$)$ & 0.29 \\
\hline Sex, F/M, n & $88 / 111$ & $49 / 65$ & $137 / 176$ & 0.832 \\
\hline \multicolumn{5}{|l|}{ Diagnosis, $\mathrm{n}$} \\
\hline Colorectal liver metastases & 144 & 103 & 247 & \\
\hline Non-colorectal liver metastases & 3 & 9 & 12 & \\
\hline Hepatocellular carcinoma & 22 & 2 & 24 & \\
\hline Cholangiocarcinoma & $25 z$ & 0 & 25 & \\
\hline Gallbladder carcinoma & 5 & 0 & 5 & \\
\hline Total & $199(63.6 \%)$ & $114(36.4 \%)$ & 313 & \\
\hline Number of lesions, one/more than one & $82 / 117$ & $63 / 51$ & $145 / 168$ & 0.016 \\
\hline
\end{tabular}

${ }^{a}$ three or more segmentectomies.

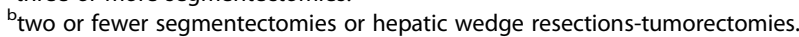

checked factors that potentially affect blood loss during parenchymal transection (gender, age, simultaneous procedures, extent of resection (major versus minor liver resection), re-do (second or third) hepatectomy, type of minor liver resection (anatomic versus non-anatomic liver resection)), the only factor that actually affected blood loss during parenchymal transection was the extent of liver resection (Table 4). In patients undergoing major hepatectomies, the mean blood loss during parenchyma transection was $274 \mathrm{ml}$ (SD $264 \mathrm{ml}$ ), while in patients undergoing minor hepatectomies it was $131 \mathrm{ml}$ (SD $55.06 \mathrm{ml})(274 \mathrm{ml}$ versus $131 \mathrm{ml} P<0.001)$. Although the PTBL was greater in non-anatomical liver resection than in anatomical minor liver resections $(124 \mathrm{ml}$ versus
$145 \mathrm{ml})$, this difference was not statistically significant $(P=0.088)$. Contrary to the PTBL, the IBL was affected by more factors (Table 4). So, in patients undergoing major hepatectomies, the IBL was $436 \mathrm{ml}$, while in patients undergoing minor hepatectomies it was $273 \mathrm{ml}$ $(P<0.001)$. Moreover, in patients who underwent re-do liver resections and in patients who underwent combined colon and hepatic resection the IBL was higher (539 $\mathrm{ml}$ versus $352 \mathrm{ml}, P<0.001$ and $501 \mathrm{ml}$ versus $358 \mathrm{ml}, P=0.001$ respectively).

Thirty-three of our patients (10.5\%) underwent blood transfusion either during the operation or during the short-term postoperative period. Seventeen of these patients underwent re-do liver resection or combined colon

Table 2 Operation characteristics

\begin{tabular}{|c|c|c|c|c|c|c|}
\hline & \multicolumn{6}{|c|}{ Diagnosis } \\
\hline & $\begin{array}{l}\text { Colorectal liver } \\
\text { metastases }\end{array}$ & $\begin{array}{l}\text { Non-colorectal } \\
\text { liver metastases }\end{array}$ & $\begin{array}{l}\text { Hepatocellular } \\
\text { carcinoma }\end{array}$ & Cholangiocarcinoma & $\begin{array}{l}\text { Gallbladder } \\
\text { carcinoma }\end{array}$ & Total \\
\hline Major hepatectomy & 144 & 3 & 22 & 25 & 5 & 199 \\
\hline $\begin{array}{l}\text { Right hepatectomy (with or without } \\
\text { combined wedge resection) }\end{array}$ & 92 & 1 & 10 & 4 & 0 & 107 \\
\hline $\begin{array}{l}\text { Left hepatectomy (with or without } \\
\text { combined wedge resection) }\end{array}$ & 36 & 2 & 10 & 3 & 0 & 51 \\
\hline Extended left hepatectomy & 4 & 0 & 0 & 7 & 0 & 11 \\
\hline Extended right hepatectomy & 12 & 0 & 2 & 11 & 5 & 30 \\
\hline Minor hepatectomy & 103 & 9 & 2 & 0 & 0 & 114 \\
\hline \multicolumn{7}{|l|}{ Anatomical hepatectomy } \\
\hline Right posterior hepatectomy & 9 & 1 & 0 & 0 & 0 & 10 \\
\hline Left lateral hepatectomy & 27 & 4 & 0 & 0 & 0 & 31 \\
\hline Bisegmentectomy & 14 & 0 & 0 & 0 & 0 & 14 \\
\hline Segmentectomy & 18 & 0 & 2 & 0 & 0 & 20 \\
\hline \multicolumn{7}{|l|}{ Non-anatomical hepatectomy } \\
\hline Wedge resections (one or multiple) & 35 & 4 & 0 & 0 & 0 & 39 \\
\hline
\end{tabular}


Table 3 Blood loss

\begin{tabular}{|c|c|c|c|c|}
\hline & \multicolumn{2}{|c|}{ Type of operation } & \multirow[b]{2}{*}{ Total (313) } & \multirow[b]{2}{*}{$P$-value } \\
\hline & Major liver resection (199) & Minor liver resection (114) & & \\
\hline \multirow[t]{2}{*}{ Intraoperative blood loss, mean (SD), (range), ml } & $436.38(346.76)$ & $272.72(286.08)$ & $376.77(334.92)$ & $<0.001$ \\
\hline & (100 to 2,400$)$ & (50 to 2,360$)$ & (50 to 2,400$)$ & \\
\hline \multirow{2}{*}{$\begin{array}{l}\text { Blood loss during parenchymal transection, mean (SD), } \\
\text { (range), ml }\end{array}$} & $273.42(264)$ & $131.23(55.06)$ & $221.63(223.66)$ & $<0.001$ \\
\hline & (90 to 2,100$)$ & (40 to 350$)$ & (40 to 2,100$)$ & \\
\hline Blood transfusion, n, (\%) & $17(8.5 \%)$ & $16(14 \%)$ & $33(10.5 \%)$ & 0.128 \\
\hline
\end{tabular}

and hepatic resection for CRLM. Excluding the patients who underwent re-do liver resection or combined colon and hepatic resection for CRLM, the blood transfusion rate for the rest of the patients was reduced to $6.7 \%$. This reduction of blood transfusion rate was predictable as the mean IBL, when we excluded these patients, decreased from $377 \mathrm{ml}$ to $336 \mathrm{ml}(P<0.001)$. Most of the transfusions were given during the operation because of heavy blood loss (up to 2,400 ml). The rest were given in the postoperative period.

Interestingly, while the IBL in major hepatectomies was higher than in minor hepatectomies $(436 \mathrm{ml}$ versus $273 \mathrm{ml}$ ) the blood transfusion rate was higher in minor liver resections although this difference was not statistically significant $(8.5 \%$ versus $14 \%, P=0.128)$. As is demonstrated in Table 1, within the group of patients with minor liver resection, the percentage of patients with
CRLM was higher than the corresponding one within the group of patients with major liver resection (103 patients with CRLM/114 minor liver resections versus 144 patients with CRLM/199 major liver resections $P<0.001$ ). This corresponds to the fact that the highest percentage of patients within the minor liver resection group had received neoadjuvant chemotherapy when compared to the major liver resection group (92/114 versus 124/199, 80.7\% versus $62.3 \%, P<0.001)$. This feature raises the possibility that the cause for higher transfusion rates in the minor liver resection group, despite the fact of a lower intraoperative blood loss, was the lower preoperative hematocrit as a result of neoadjuvant chemotherapy.

The length of hospital stay ranged from 3 to 42 days with a mean value of 6 days.

A total of 119 complications occurred in 84 patients (26.8\%). Complications and their management are

Table 4 Factors that potentially affect blood loss during parenchymal transaction and the overall amount of intraoperative blood loss

\begin{tabular}{|c|c|c|c|c|c|}
\hline Clinical factor & Number & $\begin{array}{l}\text { Blood loss during parenchyma } \\
\text { transaction mean (SD), ml }\end{array}$ & $P$-value & $\begin{array}{l}\text { Overall amount of intraoperative } \\
\text { blood loss mean (SD), ml }\end{array}$ & $P$-value \\
\hline Overall & 313 & $221.63(223.66)$ & & 376.77 (334.92) & \\
\hline \multicolumn{6}{|l|}{ Gender } \\
\hline Female & 137 & $220.8(206.77)$ & 0.789 & $358.91(294.54)$ & 0.374 \\
\hline Male & 176 & $222.27(236.55)$ & & 390.68 (363.49) & \\
\hline \multicolumn{6}{|l|}{ Age (years) } \\
\hline$\leq 60$ & 138 & $234(258.84)$ & 0.366 & $405.65(398.17)$ & 0.383 \\
\hline$>60$ & 175 & $211.9(191.64)$ & & $354.01(274.09)$ & \\
\hline \multicolumn{6}{|c|}{ Concomitant procedures } \\
\hline Yes & 41 & $188.78(75.14)$ & 0.719 & $500.98(434.44)$ & 0.001 \\
\hline No & 272 & $226.58(237.84)$ & & 358.05 (314) & \\
\hline \multicolumn{6}{|c|}{ Extent of resection } \\
\hline Major & 199 & $273.42(264)$ & $<0.001$ & $436.38(346.76)$ & $<0.001$ \\
\hline Minor & 114 & $131.23(55.06)$ & & $272.72(286.08)$ & \\
\hline \multicolumn{6}{|c|}{ Re-do hepatic resection } \\
\hline Yes & 42 & $247.14(306.27)$ & 0.228 & $539.29(436.01)$ & $<0.001$ \\
\hline No & 271 & $217.68(208.43)$ & & 351.59 (309.85) & \\
\hline \multicolumn{6}{|c|}{ Type of minor liver resection } \\
\hline Anatomic & 75 & $123.87(50.05)$ & 0.088 & $278(323.42)$ & 0.56 \\
\hline Non-anatomic & 39 & $145.38(61.85)$ & & 262.56 (198.78) & \\
\hline
\end{tabular}


summarized in Table 5. Analysis of complications between major and minor liver resections revealed no statistical differences between outcomes (Table 5). According to the Clavien Classification of Surgical Complications, only 21 patients (6.7\%) developed major complications (grade III and IV). Regarding the 16 patients (5.11\%) who developed a bile leak, 7 of them had a biliary anastomosis in addition to a liver resection.

Thirty-day mortality was $0.63 \%$ ( 2 deaths during the postoperative period). One patient died of pulmonary embolism (PE) caused by deep vein thrombosis (DVT) on postoperative day two and the other died of liver failure on postoperative day eight. The first patient, a 78year-old obese female, developed DVT and received low molecular weight heparin subcutaneously. The second patient underwent extended right hepatectomy for a Klatskin tumor and developed liver failure immediately postoperatively.

\section{Discussion}

Hemorrhage is one of the main factors contributing to morbidity and mortality in major liver resections. It is well known that, in cases of malignant tumors, perioperative administration of blood affects not only the disease-free survival period of the hepatectomized patient, through modulation of the immune response, but also the overall survival. An additional source of concern is the increased risk of infectious disease transmission through blood transfusion [6-11].
Conversely, the Pringle maneuver represents a valuable tool for managing intraoperative bleeding but places the patient at a high risk of liver damage due to ischemic reperfusion syndrome and other complications, such as splanchnic congestion and hemodynamic alterations due to vascular occlusion [18-24]. Intermittent occlusion, hemihepatic vascular occlusion [27], and ischemic preconditioning of the liver [28] have been used to minimize liver damage while simultaneously reducing intraoperative bleeding.

\section{Liver resection using CUSA $^{\circledast}$ and Aquamantys ${ }^{\circledast}$ is associated with a low transfusion rate and the necessity for the Pringle maneuver is eliminated}

The median blood loss reported from other specialized centers ranges from $155 \mathrm{ml}$ to more than $750 \mathrm{ml}$, while the perioperative blood transfusion range is from 12.6 to 65\% [29-35]. Our series has a low intraoperative blood loss $(377 \mathrm{ml})$ and a low rate of blood transfusions (10.5\%) that are comparable or even lower than the current published data from leading liver units as mentioned above [29-35].

The rate of blood transfusion reduces to $6.7 \%$ when the patients who underwent re-do liver resection or combined colon and hepatic resection for CRLM are excluded. Higher IBL in this subset of patients is likely to be secondary to higher blood loss either during difficult liver mobilization because of previous liver resection or during colonic resection.

Table 5 Postoperative complications and their management

\begin{tabular}{|c|c|c|c|c|c|}
\hline & \multicolumn{2}{|c|}{ Type of operation } & \multirow[b]{2}{*}{ Total } & \multirow[b]{2}{*}{$P$-value } & \multirow[t]{2}{*}{ Management } \\
\hline & Major liver resection (199) & Minor liver resection (114) & & & \\
\hline Complications & $59(29.6 \%)$ & $25(21.9 \%)$ & $84(26.8 \%)$ & 0.138 & \\
\hline \multirow[t]{2}{*}{ Pleural effusion } & $23(11.6 \%)$ & $10(8.8 \%)$ & $33(10.5 \%)$ & 0.440 & 28: conservatively \\
\hline & & & & & 5: drainage \\
\hline \multirow[t]{3}{*}{ Bile leak } & $9(4.5 \%)$ & $7(6.1 \%)$ & $16(5.1 \%)$ & 0.532 & 8: spontaneously resolved \\
\hline & & & & & 5: ERCP and stenting \\
\hline & & & & & 3: PTCBD \\
\hline \multirow[t]{2}{*}{ Wound infection } & $27(13.6 \%)$ & $12(10.5 \%)$ & $39(12.5 \%)$ & 0.433 & 36: antibiotics \\
\hline & & & & & 3: debridement \\
\hline Intraabdominal hemorrhage (minor) & $2(1 \%)$ & $2(1.8 \%)$ & $4(1.3 \%)$ & 0.624 & PRBC transfusion \\
\hline DVT & $4(2 \%)$ & $3(2.6 \%)$ & $7(2.2 \%)$ & 0.703 & 7: LMWH \\
\hline \multirow[t]{2}{*}{ Intraabdominal collection } & $8(4 \%)$ & $6(5.3 \%)$ & $14(4.5 \%)$ & 0.609 & 8: percutaneous drainage \\
\hline & & & & & 6: conservatively/antibiotics \\
\hline Transient hepatic failure & $6(3 \%)$ & $0(0 \%)$ & $6(1.9 \%)$ & 0.09 & Conservatively \\
\hline Thirty-day mortality & $1(0.5 \%)$ & $1(0.9 \%)$ & $2(0.6 \%)$ & & \\
\hline
\end{tabular}

DVT: deep vein thrombosis;

ERCP: endoscopic retrograde cholangiopancreatography;

LMWH: low molecular weight heparin;

PRBC: packed red blood cells;

PTCBD: percutaneous transhepatic biliary drainage. 
This series demonstrates that parenchymal transection using $\mathrm{CUSA}^{\circ}$ and Aquamantys ${ }^{\circ}$ is a standardized procedure causing minimal blood loss that removes the dangers of hepatic inflow occlusion incurred with alternative techniques such as the Pringle maneuver [20-24].

$\mathrm{CUSA}^{\circ}$ selectively destroys and aspirates parenchyma leaving vessels and biliary ducts almost intact with larger vessels and large intrahepatic bile ducts amenable to ligation or clipping. Aquamantys ${ }^{\bullet}$ delivers radiofrequency energy and causes protein denaturation. Thus, blood vessel wall collagen is shrunk, resulting in hemostasis. Hence, Aquamantys ${ }^{\circ}$ is efficient in controlling the small bleeding vessels within the liver parenchyma. The combined use of these two devices allows almost bloodless parenchymal transection without the need for hepatic inflow occlusion and ensures an efficient overall operative time (mean parenchymal transection time is 51 minutes).

Elimination of the Pringle maneuver allows transection of the liver without the previous limitation of clamp times. This results in the opportunity for meticulous parenchymal transection and gives surgical trainees the chance to develop their skills in this procedure without the previous time pressures.

This data suggests that liver resection with the use of the combined technique of saline-linked radiofrequency ablation and ultrasonic aspiration, is a useful and efficient procedure toward bloodless liver resection without the use of vascular occlusion and ensures that liver resection becomes a comparatively safer procedure.

\section{Liver resection using CUSA ${ }^{\circledR}$ and Aquamantys ${ }^{\circledR}$ is associated with low postoperative morbidity and minimum mortality}

Although the morbidity rate was $26.8 \%$, it should be noted that most of these $(20.1 \%)$ were minor complications.

We performed 199 major hepatectomies from which 41 were extended right or left hepatectomies: 42 of these hepatectomies were re-do hepatectomies. By removing the need for the Pringle maneuver we believe that low postoperative liver insufficiency rates (6 patients (1.9\%), of which 5 were transient) can be achieved. Furthermore, removal of the Pringle maneuver eliminates concerns regarding clamp time. This time comfort in combination with the use of $\mathrm{CUSA}^{\circ}$ dissection (which leaves biliary ducts intact) allows meticulous ligation or clipping of large intrahepatic biliary ducts with small biliary ducts dealt with using the heating effects of Aquamantys ${ }^{\circ}$. The above characteristics of this combined technique, we believe that is the reason of the very low rates of bile leak (5.1\%) in this series.

A low 30 -day mortality rate of $0.63 \%$ was achieved in this consecutive series; this is consistent with rates from current well-respected centers $[29,30,32,36]$.

The greatest restriction of our study is its retrospective nature and, as such, a selection bias is a possibility. This possibility of selection bias is reduced by the fact that during the period under study all three surgeons applied the same surgical technique for liver parenchymal transection to all of their patients who underwent hepatectomy. Another restriction of this study is the absence of a comparative group. Such a group was not possible as the previously used techniques for liver parenchymal transection differed between the participating institutions.

\section{Conclusion}

In conclusion, the limitations associated with a retrospective, single-institution study are acknowledged. However, the fairly large number of this series allows us to conclude that combined technique of saline-linked radiofrequency ablation and ultrasonic aspiration for liver resection is a safe method for both major and minor liver resections. The method is associated with decreased blood loss, reduced postoperative morbidity, and minimal mortality rates. We believe that this combined technique is comparable to other techniques and should be considered as an alternative.

\section{Consent}

Written informed consent was obtained from the patient for the publication of this report and any accompanying images.

\section{Abbreviations \\ IBL: intraoperative blood loss; PTBL: blood loss during parenchymal transaction; CRLM: colorectal liver metastases.}

\section{Competing interests}

The authors declare that they have no competing interests.

\section{Authors' contribution}

MS, FE and PE proposed the study. PA, NK, GA, BJ, and CF performed research. MS, FE, PA and PE performed quality control of data. FE, PA, NK, GA, $\mathrm{BJ}$, and CF performed data analysis and interpretation. FE, PA and NK wrote the first draft. MS, FE, and EP performed manuscript editing. All authors read and approved the final manuscript.

\section{Acknowledgements}

The authors would like to thank $L$ Moriarty for her contribution in editing and correcting the manuscript.

\section{Author details}

'First Department of Surgery, University of Athens Medical School, Laikon Teaching Hospital, Ay. Owrá 17, Goudi, Athens, Greece. ${ }^{2}$ Nicosia Surgical Department, Division of Hepatobiliary Pancreatic Surgery, Nicosia General Hospital, Palaios Dromos Lefkosias - Lemesou, 215, 2029 Strovolos, Nicosia, Cyprus. ${ }^{3}$ Department of Academic Surgery, Upper Gl/HPB Unit, Royal Marsden Hospital, Fulham Road, London SW3 6JJ, UK. ${ }^{4}$ The London Clinic, 20 Devonshire PI, London W1G 6BW, UK. ${ }^{5}$ Bristol Heart Institute, Severn School of Surgery, Bristol, UK.

Received: 6 April 2014 Accepted: 29 October 2014

Published: 25 November 2014

\section{References}

1. Fortner JG, Silva JS, Golbey RB, Cox EB, Maclean BJ: Multivariate analysis of a personal series of 247 consecutive patients with liver metastases from colorectal cancer. Ann Surg 1984, 199:306-316. 
2. Rosen CB, Nagorney DM, Taswell HF, Helgeson SL, Ilstrup DM, van Heerden JA, Adson MA: Perioperative blood transfusion and determinants of survival after liver resection for metastatic colorectal carcinoma. Ann Surg 1992, 216:493-504

3. Castaing D, Kanstlinger F, Habib N: Intraoperative ultrasonographic study of liver. Methods and anatomic results. Am J Surg 1985, 149(5):676-682.

4. Nagasue N, Yukaya H, Ogawa Y, Hirose S, Okita M: Segmental and subsegmental resections of the cirrhotic liver under hepatic inflow and outflow occlusion. Br J Surg 1981, 72:565-568.

5. Buell JF, Rosen S, Yoshida A, Labow D, Limsrichamrern S, Cronin DC, Bruce DS, Wen M, Michelassi F, Millis JM, Posner MC: Hepatic resection: effective treatment for primary and secondary tumors. Surgery 2000, 128(4):686-693.

6. Matsumata T, Ikeda Y, Hayashi H, Kamakura T, Taketomi A, Sugimachi K: The association between transfusion and cancer-free survival after curative resection for hepatocellular carcinoma. Cancer 1993, 72:1866-1871.

7. Yamamoto J, Kosuge T, Takayama T, Shimada K, Yamasaki S, Ozaki H, Yamaguchi N, Mizuno S, Makuuchi M: Perioperative blood transfusion promotes recurrence of hepatocellular carcinoma after hepatectomy. Surgery 1994, 115:303-309.

8. Poon RT, Fan ST, Lo CM, Ng IO, Liu CL, Lam CM, Wong J: Improving survival results after resection of hepatocellular carcinoma: a prospective study of 377 patients over 10 years. Ann Surg 2001, 234:63-70.

9. Nagorney DM, van Heerden JA, Ilstrup DM, Adson MA: Primary hepatic malignancy: surgical management and determinants of survival. Surgery 1989, 106:740-749.

10. Shimada M, Matsumata T, Akazawa K, Kamakura T, Itasaka H, Sugimachi K, Nose Y: Estimation of risk of major complications after hepatic resection. Am J Surg 1994, 167:399-403.

11. Makuuchi M, Takayama T, Gunvén P, Kosuge T, Yamazaki S, Hasegawa H: Restrictive versus liberal blood transfusion policy for hepatectomies in cirrhotic patients. World J Surg 1989, 13(5):644-648.

12. de Boer MT, Molenaar IQ, Porte RJ: Impact of blood loss on outcome after liver resection. Dig Surg 2007, 24:259-264

13. Asahara T, Katayama K, Itamoto T, Yano M, Hino H, Okamoto $Y$, Nakahara $H_{\text {, }}$ Dohi K, Moriwaki K, Yuge O: Perioperative blood transfusion as a prognostic indicator in patients with hepatocellular carcinoma. World J Surg 1999, 23(7):676-680.

14. Hanazaki K, Kajikawa S, Shimozawa N, Matsushita A, Machida T, Shimada K, Yazawa K, Koide N, Adachi W, Amano J: Perioperative blood transfusion and survival following curative hepatic resection for hepatocellular carcinoma. Hepatogastroenterology 2005, 52:524-529.

15. Abdalla EK, Noun R, Belghiti J: Hepatic vascular occlusion: which technique? Surg Clin North Am 2004, 84(2):563-585.

16. Smyrnitotis V, Farantos C, Kostopanagiotou G, Arkadopoulos N: Vascular control during hepatectomy: review of methods and results. World J Surg 2005, 29(11):1384-1396.

17. Lai PB, Lee KF, Wong J, Li AK: Techniques for liver resection: a review. Surgeon 2007, 5(3):166-174.

18. Pringle $\mathrm{JH}$ : Notes on the arrest of hepatic haemorrhage due to trauma. Ann Surg 1908, 48(4):541-549.

19. Makuuchi M, Hasegawa H, Yamazaki S: Ultrasonically guided subsegmentectomy. Surg Gynecol Obstet 1985, 161(4):346-350.

20. Grace PA: Ischaemia-reperfusion injury. Br J Surg 1994, 81(5):637-647.

21. Smyrniotis VE, Kostopanagiotou GG, Gamaletsos EL, Vassiliou JG, Voros DC, Fotopoulos AC, Contis JC: Total versus selective hepatic vascular exclusion in major liver resections. Am J Surg 2002, 183:173-178.

22. Smyrniotis VE, Kostopanagiotou GG, Contis JC, Farantos Cl, Voros DC, Kannas DC, Koskinas JS: Selective hepatic vascular exclusion versus Pringle maneuver in major liver resections: prospective study. World J Surg 2003, 27:765-769.

23. Torzilli G, Makuuchi M, Midorikawa Y, Sano K, Inoue K, Takayama T, Kubota K: Liver resection without total vascular exclusion: hazardous or beneficial. An analysis of our experience. Ann Surg 2001, 233(2):167-175.

24. Wu CC, Hwang CR, Liu TJ, P'eng FK: Effects and limitations of prolonged intermittent ischaemia for hepatic resection of the cirrhotic liver. $\mathrm{Br} J$ Surg 1996, 83(1):121-124.

25. van der Bilt JD, Livestro DP, Borren A, van Hillegersberg R, Borel Rinkes $\mathbb{H}$ : European survey on the application of vascular clamping in liver surgery. Dig Surg 2007, 24(6):423-435.
26. Balzan S, Belghiti J, Farges O, Ogata S, Sauvanet A, Delefosse D, Durand F: The '50-50 criteria' on postoperative day 5: an accurate predictor of liver failure and death after hepatectomy. Ann Surg 2005, 242(6):824-828.

27. Makuuchi M, Mori T, Gunvén P, Yamazaki S, Hasegawa H: Safety of hemihepatic vascular occlusion during resection of the liver. Surg Gynecol Obstet 1987, 164(2):155-158.

28. Clavien PA, Yadav S, Sindram D, Bentley RC: Protective effects of ischaemic preconditioning for liver resection performed under inflow occlusion in humans. Ann Surg 2000, 232(2):155-162

29. Jarnagin WR, Gonen M, Fong Y, DeMatteo RP, Ben-Porat L, Little S, Corvera C, Weber S, Blumgart LH: Improvement in perioperative outcome after hepatic resection: analysis of 1803 consecutive cases over the past decade. Ann Surg 2002, 236(4):397-407.

30. Belghiti J, Hiramatsu K, Benoist S, Massault P, Sauvanet A, Farges O: Seven hundred forty-seven hepatectomies in the 1990s: an update to evaluate the actual risk of liver resection. J Am Coll Surg 2000, 191(1):38-46.

31. Ercolani G, Ravaioli M, Grazi GL, Cescon M, Del Gaudio M, Vetrone G, Zanello M, Pinna AD: Use of vascular clamping in hepatic surgery: lessons learned from 1260 liver resections. Arch Surg 2008, 143(4):380-387. Discussion 8. Epub 2008/04/23.

32. Poon RT, Fan ST, Lo CM, Liu CL, Lam CM, Yuen WK, Yeung C, Wong J: Improving perioperative outcome expands the role of hepatectomy in management of benign and malignant hepatobiliary diseases: analysis of 1222 consecutive patients from a prospective database. Ann Surg 2004, 240(4):698-708. Discussion 10.

33. Feng ZQ, Huang ZQ, Xu LN, Liu R, Zhang AQ, Huang XQ, Zhang WZ, Dong $\mathrm{JH}$ : Liver resection for benign hepatic lesions: a retrospective analysis of 827 consecutive cases. World J Gastroenterol 2008, 14(47):7247-7251.

34. Huang ZQ, Xu LN, Yang T, Zhang WZ, Huang XQ, Cai SW, Zhang AQ, Feng $Y Q$, Zhou NX, Dong JH: Hepatic resection: an analysis of the impact of operative and perioperative factors on morbidity and mortality rates in 2008 consecutive hepatectomy cases. Chin Med J (Engl) 2009, 122(19):2268-2277.

35. Pai M, Frampton AE, Mikhail S, Resende V, Kornasiewicz O, Spalding DR, Jiao LR, Habib NA: Radiofrequency assisted liver resection: analysis of 604 consecutive cases. Eur J Surg Oncol 2012, 38(3):274-280.

36. Imamura H, Seyama Y, Kokudo N, Maema A, Sugawara Y, Sano K, Takayama T, Makuuchi M: One thousand fifty-six hepatectomies without mortality in 8 years. Arch Surg 2003, 138(11):1198-1206.

doi:10.1186/1477-7819-12-357

Cite this article as: Felekouras et al:: Combined ultrasonic aspiration and saline-linked radiofrequency precoagulation: a step toward bloodless liver resection without the need of liver inflow occlusion: analysis of 313 consecutive patients. World Journal of Surgical Oncology 2014 12:357.

\section{Submit your next manuscript to BioMed Central and take full advantage of:}

- Convenient online submission

- Thorough peer review

- No space constraints or color figure charges

- Immediate publication on acceptance

- Inclusion in PubMed, CAS, Scopus and Google Scholar

- Research which is freely available for redistribution 